\title{
Professional exposure to noise in the automotive industry
}

\author{
Constanta Rinjea (Costache) ${ }^{1}$, Oana-Roxana Chivu ${ }^{1}$ Alin Ion Țăpîrdea ${ }^{2}$, \\ Anamaria Feier ${ }^{2}$, Loredana Dascălu ${ }^{1}$, Adrian Ciprian Firu ${ }^{2}$ and Claudiu Babiș ${ }^{1}$ \\ ${ }^{1}$ University Politehnica of Bucharest, Bucharest, Romania \\ ${ }^{2}$ Universitatea Politehnica Timișoara - IMF, România \\ E-mail: virlan_oana@gmail.com
}

\begin{abstract}
The automotive industry is one of the most developed industries in the world and is the engine of the economy of many states. This paper aims to present the values of the noise level to which a worker is exposed, in a factory in the automotive industry. The purpose of these measurements is to evaluate the impact of the noise produced by the activities that take place on the factory site and to verify the noise level if it falls within the limits in force at the moment. To perform the measurements, 6 areas of the factory were identified; 3 indoor areas: production area, office area and metrology laboratory area and 3 outdoor areas: smoking area, truck loading area and employee entry area.

Keywords: Noise, production, noise pollution, office, metrology laboratory.
\end{abstract}

\section{Introduction}

This industry is characterized by a high consumption of raw materials to produce cars, trucks, and buses. There are companies that have units with a complete manufacturing cycle, they are also the big car manufacturers, but there are other companies that only deal with the assembly and production of parts.[1]

Improving worker productivity, health and safety at work are major concerns of the industry.

According to [4], productivity was one of the most important factors affecting the overall performance of any organization, from small businesses to entire nations. Increased attention has been focused on the relationship between the work environment and productivity since the ' 90 .

Laboratory and field studies have shown that physical and chemical factors in the work environment could have a significant impact on human health and performance and, consequently, on productivity. Noise in the workplace has a significant relationship with worker satisfaction and performance. [5], [6], [7].

\section{The current state}

Noise pollution is a topical issue worldwide.

Following studies by the World Health Organization (WHO), it has been found that half of Europeans live their lives in a continuous noise, and more than a trinity suffer from insomnia as a result of noise pollution. Noise is a harmful factor, met frequently in several industrial activities.

Noise is a loud sound that is measured in decibels $(\mathrm{dB})$. The $\mathrm{dB}$ is used as a unit of measurement to describe the intensity of sound, and $\mathrm{dB}(\mathrm{A})$ is based on the intensity of sound and how the human ear reacts. It also has negative effects on work performance in terms of cognitive skills, memory, motor skills and perception (Sanders and McCormick, 1993). Noise affects people's nervous system and hearing, weakens employees' concentration, reduces attention and reaction skills. There is a possibility of discomfort such as fatigue, sleep disorders and headaches. The most important effect of noise is 
hearing loss. The duration of exposure to noise determines the severity of the disease, in addition to frequency, intermittent or persistent disease, age and vulnerability.[8]

\section{Monitoring the noise level in a factory from the automotive industry}

Measurements were made to determine the noise level in 6 areas located inside and outside the factory. The equipment used to perform the measurements is the iNCH Smartphone application. This is a unique application, developed by engineer Robert Bosch and is a basic tool to support noise assessments. The instrument comes with a sound level measurement module easy to use, general level mode as a function of time and data mode as a function of time. The application basically uses microphones and accelerometers built into a Smartphone.

Contain the latest calibration values for most mobile phone ranges (because every mobile phone is different in its own way). There is also a sound calibration tool included to improve the accuracy of noise measurement.[2]

The specific input of the noise analyser is sound, vibrational energy of a certain frequency and intensity.

For the human ear, the frequency of sounds heard is between 20 and 20,000 Hz (Hertz).

At the same time, in order to be heard, the sound must have a minimum level of intensity (minimum threshold) and not exceed a maximum intensity, over which the sound becomes harmful, and the auditory sensation is altered becoming painful (painful threshold for the ear). Noise has a complex action on the human body.

To determine the noise level in the factory, the sound measurements were performed inside the factory in 6 areas, 3 outside and 3 inside.

Table 1. Paragraph from standard SR 10009:2017[9]

\begin{tabular}{|l|c|}
\hline Street type / Space considered & $\begin{array}{c}\text { Noise level } \\
{[\mathrm{dB}]}\end{array}$ \\
\hline $\begin{array}{l}\text { Stadiums, cinemas, and open-air theaters, cultural, sports and outdoor entertainment } \\
\text { events }\end{array}$ & 90 \\
\hline Car parking & 70 \\
\hline Recreation and rest areas, medical and balneo-climatic treatment & 45 \\
\hline Markets, commercial spaces, outdoor restaurant & 65 \\
\hline Industrial units and spaces with activities assimilated to industrial activities & $\mathbf{6 5}$ \\
\hline Street of technical category IV, of local service & 60 \\
\hline Street of technical category III, collection & 65 \\
\hline Technical category II street, connecting & 70 \\
\hline
\end{tabular}

Identified noise sources:

- supply activities carried out behind the factory;

- production area noise (Figure 1).

The total noise of a supply cycle provides from 3 factors:

- noise produced by the road train engine;

- truck loading noise (Figure 5);

- noise from waste collection;

- background noise.

The background noise is represented by the road traffic from a nearby boulevard, present for the entire duration of the determinations and the noise coming from the neighbouring industrial units.

In Figures 1, 2, 3, mentioned above, it can be see the determination of the noise level in the production area, office and metrology laboratory; areas inside the factory where the values that was measure, are within the limits in force.

Tables 2, 3, 4 illustrate the average, the minimum and the maximum values from which it results that they fall within the limits. 
Also, figures 4, 5, 6 represent the areas outside the factory, the smoking area, the truck loading area and the employee entry area.

Both the values determined in the 3 figures and in tables 5, 6, 7 show that they have a maximum allowed value at the property limit of $65 \mathrm{~dB}$ (A) according to SR-10009-2017 and table 1.

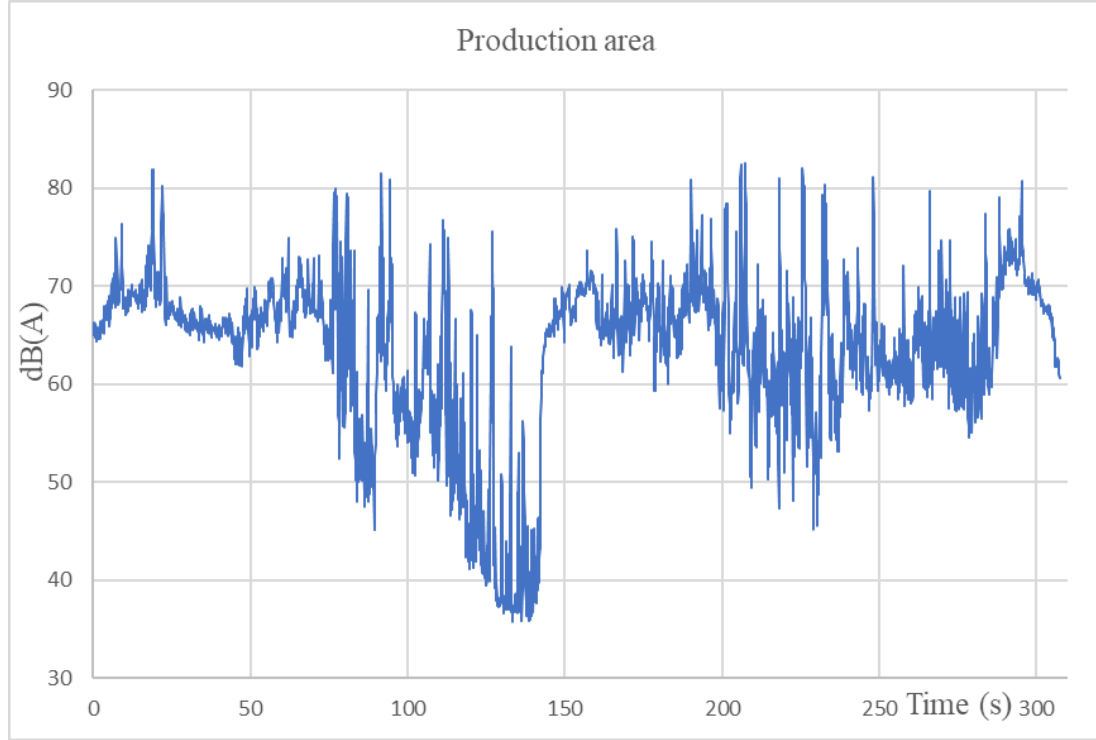

Figure 1. Determination of production noise

Table 2. Noise level in the production area

\begin{tabular}{|l|l|}
\hline Average value & $63,39 \mathrm{~dB}(\mathrm{~A})$ \\
\hline Minimum value & $35,80 \mathrm{~dB}(\mathrm{~A})$ \\
\hline Maximum value & $82,52 \mathrm{~dB}(\mathrm{~A})$ \\
\hline
\end{tabular}

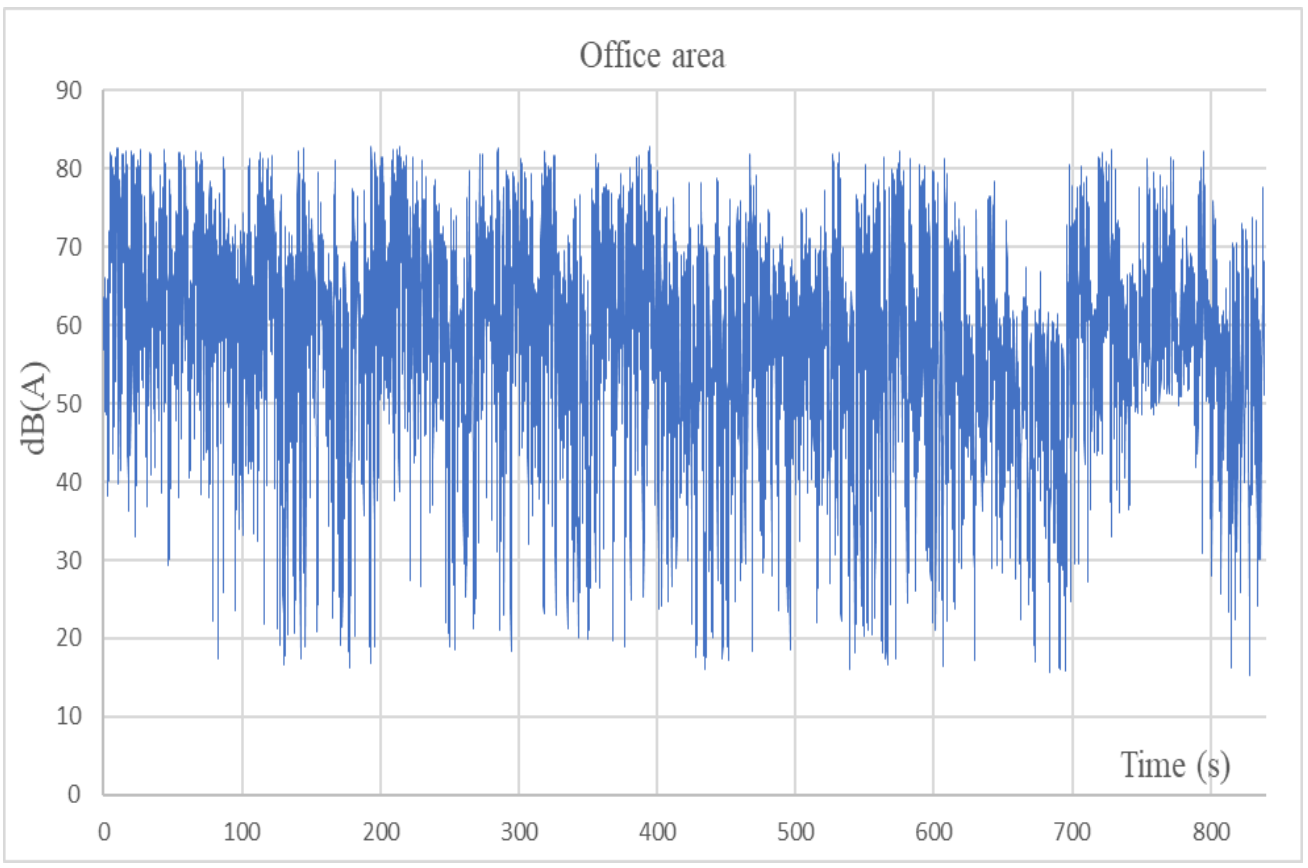

Figure 2. Determination office noise 
Table 3. Noise level in the office area

\begin{tabular}{|l|c|}
\hline Average value & $58,08 \mathrm{~dB}(\mathrm{~A})$ \\
\hline Minimum value & $15,26 \mathrm{~dB}(\mathrm{~A})$ \\
\hline Maximum value & $82,90 \mathrm{~dB}(\mathrm{~A})$ \\
\hline
\end{tabular}

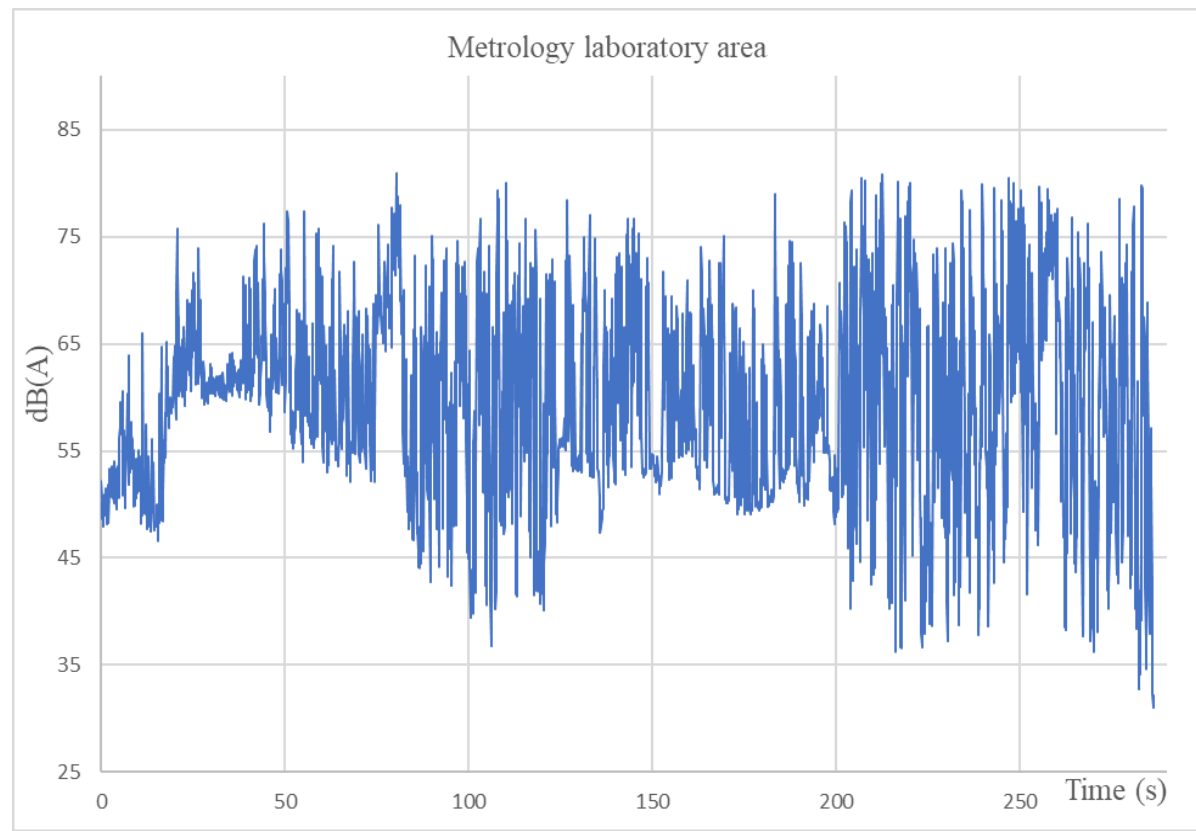

Figure 3. Noise in the metrology laboratory

Table 4. Noise level in the metrology laboratory

\begin{tabular}{|l|l|}
\hline Average value & $59,44 \mathrm{~dB}(\mathrm{~A})$ \\
\hline Minimum value & $31,00 \mathrm{~dB}(\mathrm{~A})$ \\
\hline Maximum value & $80,93 \mathrm{~dB}(\mathrm{~A})$ \\
\hline
\end{tabular}

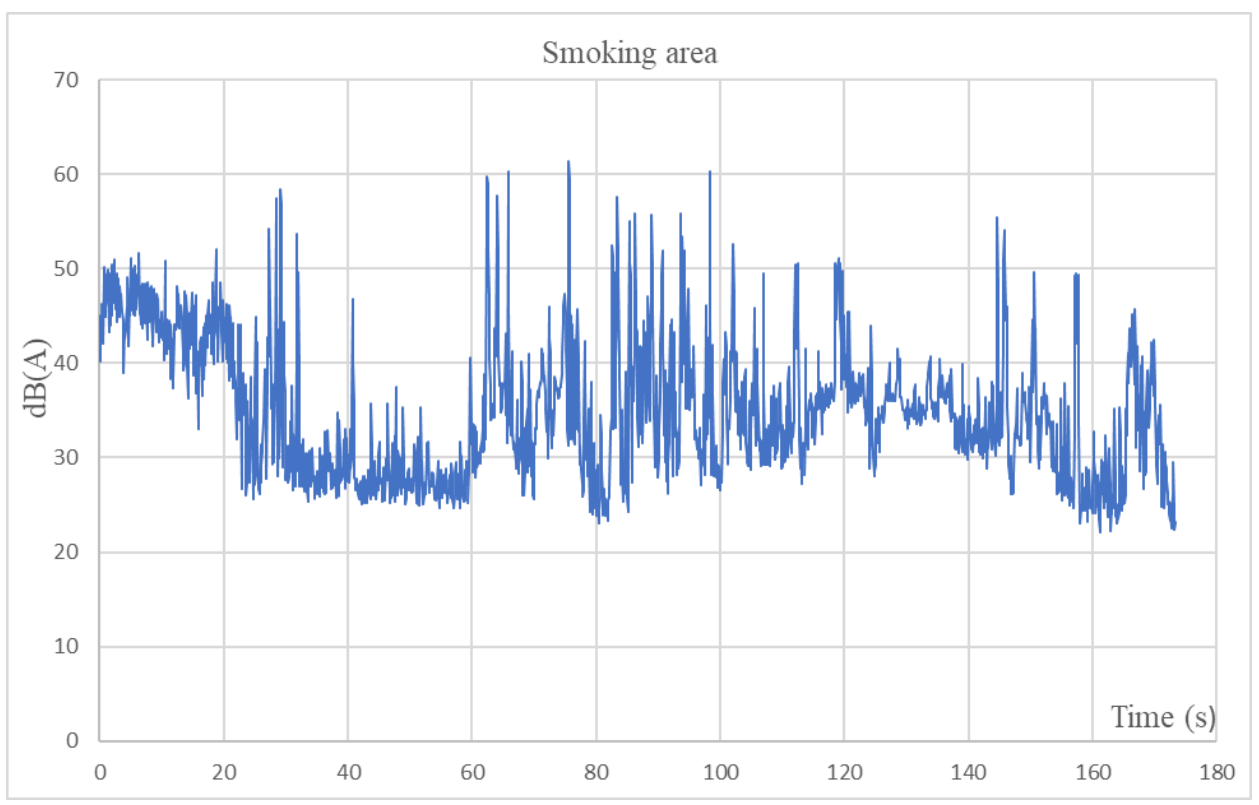

Figure 4. Noise level in the smoking area 
Table 5. Noise level in the smoking area

\begin{tabular}{|c|c|}
\hline Average value & $34,90 \mathrm{~dB}(\mathrm{~A})$ \\
\hline Minimum value & $22,11 \mathrm{~dB}(\mathrm{~A})$ \\
\hline Maximum value & $61,35 \mathrm{~dB}(\mathrm{~A})$ \\
\hline
\end{tabular}

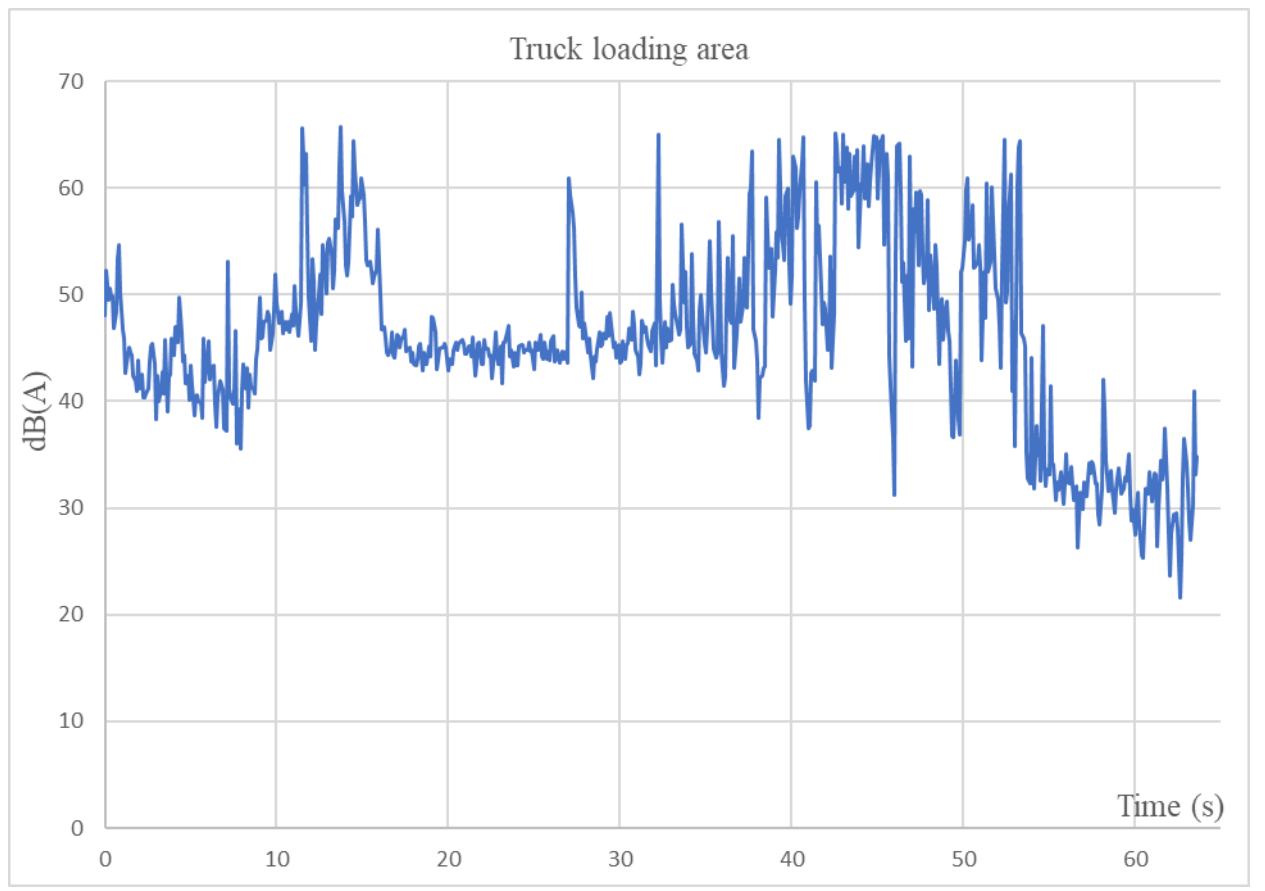

Figure 5. Determination of noise in the loading area of trucks

Table 6. Noise level in the truck loading area

\begin{tabular}{|l|l|}
\hline Average value & $46,04 \mathrm{~dB}(\mathrm{~A})$ \\
\hline Minimum value & $21,54 \mathrm{~dB}(\mathrm{~A})$ \\
\hline Maximum value & $65,78 \mathrm{~dB}(\mathrm{~A})$ \\
\hline
\end{tabular}

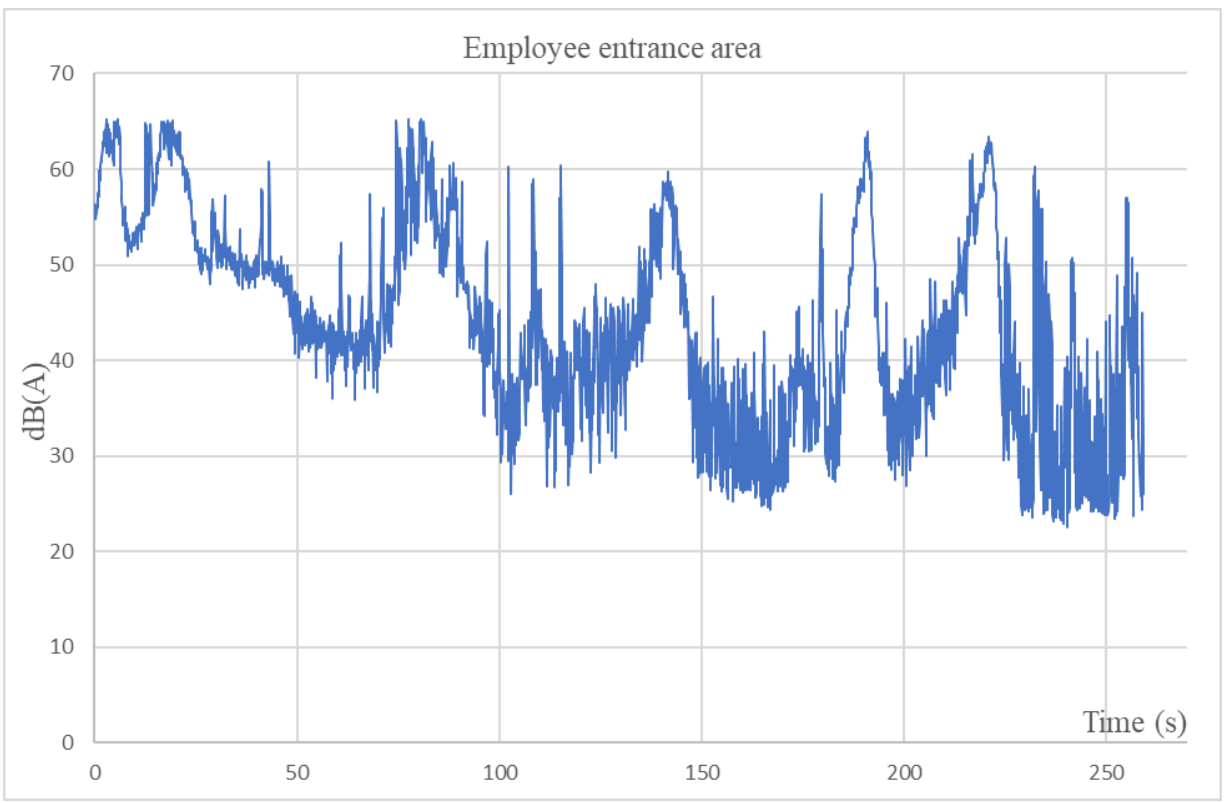

Figure 6. Determination the noise in the employee entrance area 
Table 7. Noise level in the truck loading area

\begin{tabular}{|l|c|}
\hline Average value & $43,84 \mathrm{~dB}(\mathrm{~A})$ \\
\hline Minimum value & $22,64 \mathrm{~dB}(\mathrm{~A})$ \\
\hline Maximum value & $65,23 \mathrm{~dB}(\mathrm{~A})$ \\
\hline
\end{tabular}

\section{Conclusion}

In conclusion, it can be specified that, at the factory limit, outside and inside, the noise level generated by the operation of various machinery / equipment, is manifested inside to the factory, not exceeding the limitations in force.

The measurements were performed with the noise sources on, in normal activity.

The source of noise is the supply activity that takes place using trucks. Another source of noise is represented by the production process.

The background noise is represented by the other activities in the area (cleaning, maintenance, etc.).

The measurement was performed by recording on certain time intervals and marking the events and the type of noise (source or background).

The traffic and the own activities in the area generate the increase of the noise level.

According to SR-10009-2017, industrial activities have a maximum allowed value at the property limit of $65 \mathrm{~dB}(\mathrm{~A})$.

Also, the noise level, generated by the activities inside the factory, are keep below the limits in force below $87 \mathrm{~dB}$.

Comparing the results of the measurements with the limitations presented in Table 1, it is observed that there are values that are found in all 3 areas located at the boundary of the unit, below $65 \mathrm{~dB}(\mathrm{~A})$, which is the limit for industrial premises in urban areas.

Near the noise sources, the noise level is higher and decreases with increasing distance from the noise source.

\section{References}

[1]. https://en.wikipedia.org/wiki/Automotive_industry

[2] .https://appcenter.bosch.com/applications/3c970d10-b16f-4802-ad1d-869f25df6a60

[3]. Ismail, A. R., Rani, M. R. A., Makhbul Z. K. M. and Deros, B. M., The Effect of Humidity on the Worker Productivity: A Study at Malaysia Electronics Industry

[4]. Fisk W.J. and Rosenfeld A.H. 1997 Estimates of improved productivity and health from better indoor environments. Indoor Air 7: 158-172.

[5]. Fisk, W. J. 2000 Health and Productivity Gains From Better Indoor Environments and Their Relationship with Building Energy Efficiency. Annual Review of Energy \& The Environment. 25(2): 537-566.

[6]. Marshall, L., Erica, W., Alan, A. and Sanborn, M. D. 2002 Identifying and Managing Adverse Enviromental Health Effects: 1. Taking an Exposure History Canadian Medical Association Journal. 166(8): 1049-1055.

[7]. Tarcan, E. Varol, E.S. and Ates, M. 2004 A Qualitative Study of Facilities and Their Enviromental Performance Management of Environmental Quality: An International Journal. 15(2): 154173.

[8]. Berna Haktanirlar Ulutas, Firat, N. Ozkan Osmangazi Analysis of environmental conditions in metal industry Emin Kahya*, University, Faculty of Engineering and Architecture, Dept. of Industrial Engineering, Eskisehir, Turkey

[9]. SR 10009,2017, Acoustics; Permissible noise level limits from the environment 